\title{
ВMJ Global Health Severe malnutrition or famine exposure in childhood and cardiometabolic non- communicable disease later in life: a systematic review
}

\author{
Kelsey Grey (D) , ${ }^{1}$ Gerard Bryan Gonzales, ${ }^{2}$ Mubarek Abera, ${ }^{3}$ Natasha Lelijveld, ${ }^{4}$ \\ Debbie Thompson, ${ }^{5}$ Melkamu Berhane, ${ }^{6}$ Alemseged Abdissa, ${ }^{7}$ Tsinuel Girma, ${ }^{6}$ \\ Marko Kerac (10 ${ }^{8}$
}

\begin{abstract}
To cite: Grey K, Gonzales GB, Abera M, et al. Severe malnutrition or famine exposure in childhood and cardiometabolic noncommunicable disease later in life: a systematic review. BMJ Global Health 2021;6:e003161. doi:10.1136/ bmjgh-2020-003161
\end{abstract}

Handling editor Seye Abimbola

- Additional material is published online only. To view, please visit the journal online (http://dx.doi.org/10.1136/ bmjgh-2020-003161).

Received 14 June 2020 Revised 8 December 2020 Accepted 14 December 2020

Check for updates

(C) Author(s) (or their employer(s)) 2021. Re-use permitted under CC BY. Published by BMJ.

For numbered affiliations see end of article.

Correspondence to

Kelsey Grey;

kelsey.grey@alumni.Ishtm.ac.uk

\section{ABSTRACT}

Introduction Child malnutrition (undernutrition) and adult non-communicable diseases (NCDs) are major global public health problems. While convincing evidence links prenatal malnutrition with increased risk of NCDs, less is known about the long-term sequelae of malnutrition in childhood. We therefore examined evidence of associations between postnatal malnutrition, encompassing documented severe childhood malnutrition in low/middleincome countries (LMICs) or famine exposure, and later-life cardiometabolic NCDs.

Methods Our peer-reviewed search strategy focused on 'severe childhood malnutrition', 'LMICs', 'famine', and 'cardiometabolic NCDs' to identify studies in Medline, Embase, Global Health, and the Cumulative Index to Nursing and Allied Health Literature (CINAHL) databases. We synthesised results narratively and assessed study quality with the UK National Institute for Health and Care Excellence checklist.

Results We identified 57 studies of cardiometabolic NCD outcomes in survivors of documented severe childhood malnutrition in LMICs $(n=14)$ and historical famines $(n=43)$. Exposure to severe malnutrition or famine in childhood was consistently associated with increased risk of cardiovascular disease (7/8 studies), hypertension (8/11), impaired glucose metabolism (15/24) and metabolic syndrome (6/6) in later life. Evidence for effects on lipid metabolism (6/11 null, $5 / 11$ mixed findings), obesity ( $3 / 13$ null, $5 / 13$ increased risk, $5 / 13$ decreased risk) and other outcomes was less consistent. Sex-specific differences were observed in some cohorts, with women consistently at higher risk of glucose metabolism disorders and metabolic syndrome.

Conclusion Severe malnutrition or famine during childhood is associated with increased risk of cardiometabolic NCDs, suggesting that developmental plasticity extends beyond prenatal life. Severe malnutrition in childhood thus has serious implications not only for acute morbidity and mortality but also for survivors' longterm health. Heterogeneity across studies, confounding by prenatal malnutrition, and age effects in famine studies preclude firm conclusions on causality. Research to improve understanding of mechanisms linking postnatal malnutrition and NCDs is needed to inform policy and programming to improve the lifelong health of severe malnutrition survivors.

\section{Key questions}

What is already known?

- Many countries face a large 'double burden' of malnutrition: high prevalence of child undernutrition combined with a growing epidemic of overweight/ obesity and associated cardiometabolic noncommunicable diseases (NCDs).

- Convincing evidence for the Developmental Origins of Health and Disease hypothesis links prenatal malnutrition with increased long-term NCD risk, but less is known about the effects of severe malnutrition in childhood on NCD risk.

\section{What are the new findings?}

- Our review identified 57 studies examining NCD outcomes among survivors of historical famines $(n=43)$ and severe childhood malnutrition $(n=14)$.

- Severe malnutrition and famine exposure in childhood were consistently associated with increased risk of cardiovascular disease, impaired glucose metabolism, and metabolic syndrome (MetS). Some sex-specific effects were observed, with famineexposed women at higher risk of glucose metabolism disorders and MetS.

- Heterogeneity across studies, uncontrolled confounding by prenatal malnutrition, and inadequate statistical adjustment for age effects in some famine studies were key limitations.

\section{INTRODUCTION}

Severe malnutrition (undernutrition) in childhood and adult non-communicable diseases (NCDs) are two of the world's most urgent public health problems. ${ }^{1}$ In all its forms, malnutrition accounts for some $45 \%$ of all mortality in children under 5 years. ${ }^{2}$ Severe malnutrition, particularly wasting, threatens the survival of an estimated 47 million children under 5 in low/middleincome countries (LMICs). ${ }^{1}$ In contrast, obesity-related NCDs are emerging as a 


\section{Key questions}

What do the new findings imply?

- Preventing and treating severe malnutrition in children are not only important in their own right but also play a potentially important role in preventing NCDs. This is especially important in the context of impending global hunger related to the COVID-19 pandemic.

- Further research into mechanisms linking severe malnutrition in childhood with NCDs is needed to inform policy, programming, and patient management strategies that support long-term health in survivors of early-life malnutrition.

leading cause of death in these settings, with nearly three quarters of all NCD deaths occurring in LMICs (28 million) including most premature deaths $(82 \%){ }^{3}$ While convincing evidence for the Developmental Origins of Health and Disease (DOHaD) hypothesis links prenatal malnutrition with increased NCD risk later in life, less is known about the long-term sequelae of severe malnutrition during postnatal periods of developmental plasticity such as childhood and adolescence. However, it is biologically plausible that malnutrition during these crucial periods of postnatal growth and development may also have lasting effects on survivors' health. ${ }^{4}$

At present, efforts to address severe childhood malnutrition are focused on community-based management with ready-to-use therapeutic foods along with inpatient treatment of complicated cases to prevent short-term mortality. ${ }^{5}$ As these efforts reduce case-fatality rates and global child mortality declines, considering the longterm health consequences of severe malnutrition and effects of therapeutic foods is increasingly important. ${ }^{67}$ Tackling NCDs is a priority under Sustainable Development Goal 3 (Good health and well-being), which aims to 'reduce by one third premature mortality from NCDs through prevention and treatment' by $2030 .{ }^{8}$ As LMICs face the financial and social penalties of the increasing NCD burden, it is imperative to prioritise NCD prevention. This area of research is especially topical as early evidence suggests that severe malnutrition in childhood may be linked with increased NCD risk for survivors. ${ }^{9} 10$

While a narrative review examining evidence of differences in cardiometabolic risk between marasmus and kwashiorkor survivors was conducted by Boyne et al in 2017, no systematic review examining evidence on NCD outcomes following severe malnutrition or famine exposure in childhood currently exists in the literature. ${ }^{11}$ As more children survive severe malnutrition globally, greater knowledge in this area is key to informing improved policy and programming around severe childhood malnutrition that reduce NCD risk. This review brings together evidence from studies of survivors of documented severe childhood malnutrition in LMICs or famines to present a synthesis of current knowledge on this topic.

\begin{tabular}{|c|c|c|}
\hline Country & Setting & $\begin{array}{l}\text { No. of } \\
\text { studies }\end{array}$ \\
\hline \multicolumn{3}{|c|}{ Documented severe malnutrition studies } \\
\hline Jamaica & $\begin{array}{l}\text { Tropical Metabolism Research Unit, } \\
\text { Kingston }\end{array}$ & 3 \\
\hline Senegal & $\begin{array}{l}\text { Urban nutritional rehabilitation } \\
\text { units, Thiès and Dakar }\end{array}$ & 2 \\
\hline Malawi & $\begin{array}{l}\text { Nutrition ward at central hospital, } \\
\text { Blantyre }\end{array}$ & 2 \\
\hline Uganda & $\begin{array}{l}\text { Infantile Malnutrition Research } \\
\text { Unit, Kampala }\end{array}$ & 2 \\
\hline Mexico & Paediatric hospitals, Mexico City & 2 \\
\hline Ethiopia & $\begin{array}{l}\text { Urban health centres, Jimma and } \\
\text { Gondar }\end{array}$ & 1 \\
\hline Gambia & $\begin{array}{l}\text { Medical Research Council field } \\
\text { station, West Kiang }\end{array}$ & 1 \\
\hline Kenya & Rural hospital, Kijabe & 1 \\
\hline Total & & 14 \\
\hline \multicolumn{3}{|l|}{ Famine studies } \\
\hline China & Great Chinese Famine (1959-1961) & 30 \\
\hline The Netherlands & Dutch Hunger Winter (1944-1945) & 4 \\
\hline Russia & Siege of Leningrad (1941-1944) & 3 \\
\hline England & $\begin{array}{l}\text { German occupation of Channel } \\
\text { Islands (1944-1945) }\end{array}$ & 2 \\
\hline Ukraine & Holodomor famine (1932-1933) & 2 \\
\hline Bangladesh & Post-monsoon famine (1974-1975) & 1 \\
\hline Nigeria & Biafran civil war (1967-1970) & 1 \\
\hline Total & & 43 \\
\hline
\end{tabular}

\section{METHODS}

\section{Protocol and registration}

This review follows the Preferred Reporting Items for Systematic Reviews and Meta-Analyses guidelines. $^{12}$ The protocol was registered on PROSPERO (ID: CRD42019145683).

\section{Search strategy}

A peer-reviewed search strategy focused around 'severe childhood malnutrition, 'LMICs', 'famine', and 'cardiometabolic NCDs' was used to identify studies in Medline, Embase, Global Health, and CINAHL databases (search strategy in online supplemental file 1). Reference lists of studies identified through database searching were handsearched for additional studies. All final searches were run on 31 July 2019.

\section{Eligibility criteria}

Human studies published in English were assessed for eligibility against the following criteria:

Population: older children and adults who survived an episode of documented severe malnutrition in LMICs or famine exposure in childhood and adolescence (defined as $0-18$ years of age). 


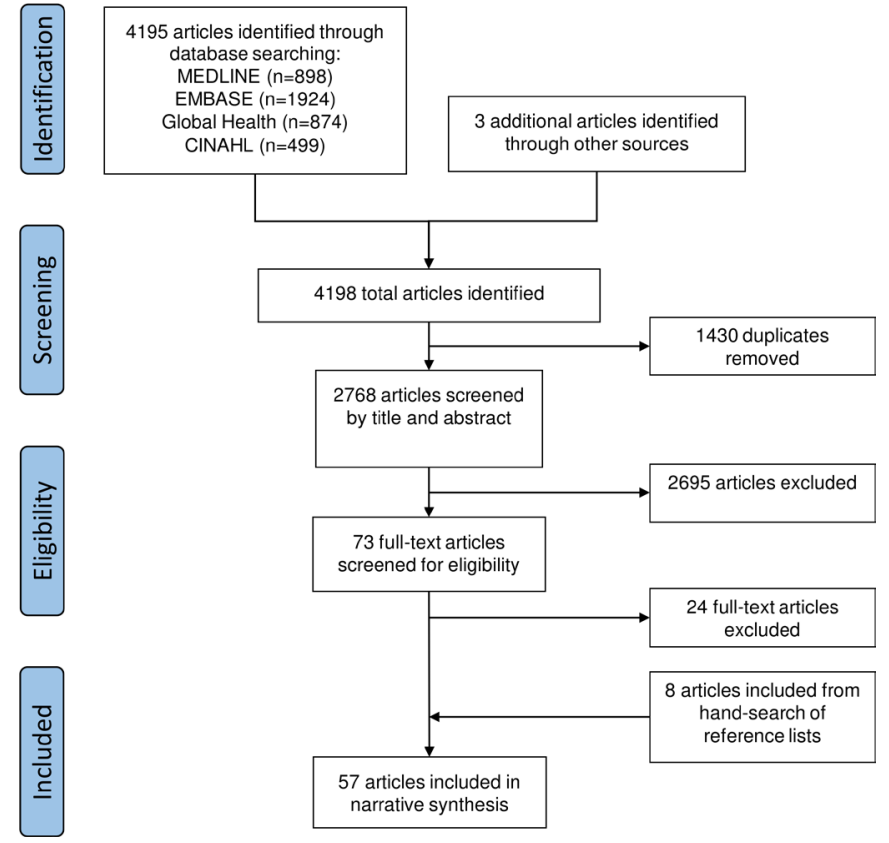

Figure 1 Preferred Reporting Items for Systematic Reviews and Meta-Analyses flow diagram of the study selection process.

Exposure: exposure definitions included two closely related groups: (1) documented severe malnutrition in childhood defined according to standard classifications based on low weight-for-height, low weight-for-age (WFA), low mid-upper arm circumference (MUAC), or nutritional oedema, or (2) famine conditions defined by severe food insecurity in the local area or country setting. Although severe stunting is a form of severe malnutrition, we excluded studies that considered stunted children alone as the association between stunting and increased NCD risk has been described elsewhere. ${ }^{13}$

Comparators: a comparison group unexposed to documented severe malnutrition or famine in childhood was preferred but not required.

Outcomes: a range of cardiometabolic NCD outcomes (eg, impaired glucose metabolism, dyslipidaemia, hypertension) was considered if they were based on an objective clinical outcome measured at least 1 year after exposure to severe malnutrition or famine. All study designs were eligible. Grey literature and unpublished studies were excluded.

\section{Screening and selection}

Studies were screened for inclusion by a single author (KG) using a two-step process. First, potentially relevant studies were identified by screening titles and abstracts against the eligibility criteria. The full-text articles of identified studies were then reassessed to confirm their suitability for inclusion.

\section{Risk-of-bias assessment}

A risk-of-bias assessment at study level was conducted using the appraisal checklist for quantitative studies reporting correlations and associations from the UK
National Institute for Health and Care Excellence. This 16-item checklist facilitates assessment of a study's internal and external validity (EV) based on key aspects of study design, including characteristics of study participants, definition of independent variables, outcomes assessed, and analytical methods. ${ }^{14}$ Each study is assigned an overall quality grade for internal validity and another for $\mathrm{EV}$ as follows: $(\bullet \bullet)$ all or most of the checklist criteria have been fulfilled, where they have not been fulfilled the conclusions are very unlikely to alter, $(\bullet)$ some of the checklist criteria have been fulfilled, where they have not been fulfilled, or not adequately described, the conclusions are unlikely to alter, or (-) few or no checklist criteria have been fulfilled and the conclusions are likely or very likely to alter.

\section{Data extraction, analysis, and reporting}

Data were extracted using a standardised Microsoft Excel (2016) template that was piloted and adapted during the review process. The data extracted included: publication year, study design, study population, exposure definition, time since exposure, control group characteristics, outcomes, analytical methods, and key findings.

Due to the wide range of included NCD-related outcomes, meta-analysis was impossible. Therefore, a narrative synthesis was carried out for each outcome with a focus on any differential effects of exposure between subgroups where data allowed (eg, sex-specific or agespecific differences). Effect sizes for similar outcomes were compared across studies to identify areas of agreement or inconsistency in the results. Data from studies of famine survivors and documented severe childhood malnutrition were analysed separately to account for the different nature of the exposures.

\section{Patient and public involvement}

Neither patients nor the public were involved in this research.

\section{RESULTS}

\section{Search results}

The search yielded 2765 articles after removing duplicates. Three articles identified by senior authors were included for a total of 2768 articles for screening by title and abstract, which resulted in 73 articles for full-text appraisal. Another 24 articles were then excluded as they did not meet inclusion criteria. Eight eligible articles were identified from hand-searching reference lists for a total of 57 included articles (figure 1).

\section{Study characteristics}

A total of 57 articles published between 1968 and 2019 were included, with 31 (54\%) published between 2015 and 2019. Among these studies, 14 (25\%) examined NCD outcomes among survivors of documented severe childhood malnutrition in LMICs and $43(75 \%)$ studied famine survivors. Famine studies were predominantly retrospective cohorts $(\mathrm{n}=31 ; 72 \%)$, followed 
by prospective cohorts $(\mathrm{n}=7 ; 16 \%)$ and cross-sectional studies $(n=5 ; 12 \%)$. Studies of documented severe malnutrition survivors were prospective cohorts $(\mathrm{n}=12 ; 86 \%)$ or case-control studies $(\mathrm{n}=2 ; 14 \%)$.

\section{Study population and context}

The studies represent findings from 15 countries; however, most were conducted among survivors of the Great Chinese Famine ( $\mathrm{n}=30 ; 53 \%$; table 1$)$.

Participants in studies of documented severe childhood malnutrition were selected from clinic records of treatment for severe childhood malnutrition. However, in two casecontrol studies examining the exposure history of patients with diabetes, participants were recruited from outpatient clinics. $^{1516}$

Famine studies were conducted with participants exposed to famines between 1932 and 1970 (table 1). Participants in these studies were usually drawn from cross-sectional surveys or cohorts initiated for other studies. In some cases, participants were selected from physical examination records at health facilities or registries of patients with diabetes or siege survivors. In the Nigerian study, participants were recruited from central markets. ${ }^{17}$

In studies of documented severe childhood malnutrition, sample sizes ranged from 15 to 320 (median: 52; IQR: 34-100), whereas sample sizes varied between 62 and 105 374 for famine studies (median: 3548; IQR: 705-5920). For two of the famine studies, the number of cases and controls was not reported, and so the total number of participants was taken as the sample size. ${ }^{18} 19$ Gender balance among participants varied across studies from $30 \%$ to $83 \%$ female; however, three studies had male-only samples, six studies had only female participants and information on participant gender was unavailable for three studies. ${ }^{20-22}$

\section{Definitions of exposure to severe childhood malnutrition and famine}

Various criteria were used to define severe malnutrition exposure, with admission to nutritional rehabilitation units based on WHO, Wellcome and Gomez classifications being the most common. Three studies used clinical diagnosis of marasmus or kwashiorkor without precise definitions, ${ }^{202324}$ and two used self-reports of severe childhood malnutrition. ${ }^{15} 16$ In the study by Moore et al (2001), childhood WFA z-scores for all participants were analysed against NCD outcomes regardless of whether they classified as malnourished. ${ }^{25}$

Famine exposure was most frequently defined according to participants' birthdates and residency in famine-affected areas during childhood. However, five studies used individual self-reports of famine exposure. ${ }^{26-30}$ Excess mortality was often used to approximate levels of famine severity in different locations. Due to the different nature of the exposures, study characteristics have been presented separately for famine studies (table 2) and documented severe malnutrition studies (table 3) along with the results of the risk-of-bias assessment. Detailed tables containing effect sizes and $p$-values can be found in online supplemental file 2. An alternative version of table 2 categorising famine studies by study design is in online supplemental file 3.

\section{Outcomes assessed}

Included studies examined the impact of severe childhood malnutrition or famine exposure on one or more cardiometabolic NCD outcomes, including: glucose metabolism, cardiovascular disease (CVD), dyslipidaemia, non-alcoholic fatty liver disease (NAFLD), blood markers of cardiometabolic disease (eg, acute phase proteins, cortisol), physical capacity, metabolic syndrome, chronic kidney disease, epigenetic profile, telomere length, thyroid function, and anthropometry. Outcomes were assessed between 2 and 70 years post exposure in studies of documented severe malnutrition and 28-70 years post exposure in famine studies.

\section{Results by outcome}

Because many of the studies presented in tables 2 and 3 reported findings on various outcomes, the results are summarised by outcome for clarity:

\section{Cardiovascular outcomes \\ Famine studies}

Famine exposure during childhood and adolescence was associated with increased risk of CVD (eg, myocardial infarction, coronary artery calcification) in $7 / 8$ studies from the UK, China, Russia and the Netherlands, ${ }^{22} 27$ 29-33 with only one study of Leningrad Siege survivors finding no difference in the prevalence of CVD. ${ }^{34} \mathrm{~A}$ sex-specific effect was noted in $2 / 3$ studies; one study reported increased risk of peripheral arterial disease among women exposed to the Dutch Hunger Winter in adolescence, and another found higher mortality from cerebrovascular disease and ischaemic heart disease in men exposed to the Leningrad Siege at ages 9-15 years and 6-8 years, respectively. ${ }^{31} 33$

There was also consistent evidence of positive association between famine exposure and elevated blood pressure (BP) and hypertension in 8/11 studies from China, Nigeria and Russia. ${ }^{172} 3235-39$ However, three Chinese studies found no difference in BP or hypertension risk between unexposed controls and those exposed to famine in infancy, early childhood, and late childhood, respectively. ${ }^{3040}$ While the findings primarily indicate that famine exposure during infancy and childhood are associated with increased BP in adulthood, the two studies that included adolescents found positive associations between adolescent famine exposure (9-15 years) and increased $\mathrm{BP}^{32} 33$

\section{Documented severe malnutrition studies}

Cardiovascular outcomes examined in studies of severe childhood malnutrition survivors largely focused on BP. These studies found mixed effects on BP outcomes, with one Jamaican study finding higher diastolic blood pressure $(\mathrm{dBP})(\mathrm{d}=4.3 \mathrm{~mm} \mathrm{Hg} ; \mathrm{p}=0.007)$, but no differences in sBP, in survivors compared with controls at $\sim 30$ years, while a Mexican study found lower $\mathrm{dBP}(\mathrm{p}=0.001)$ and $\mathrm{sBP}$ 


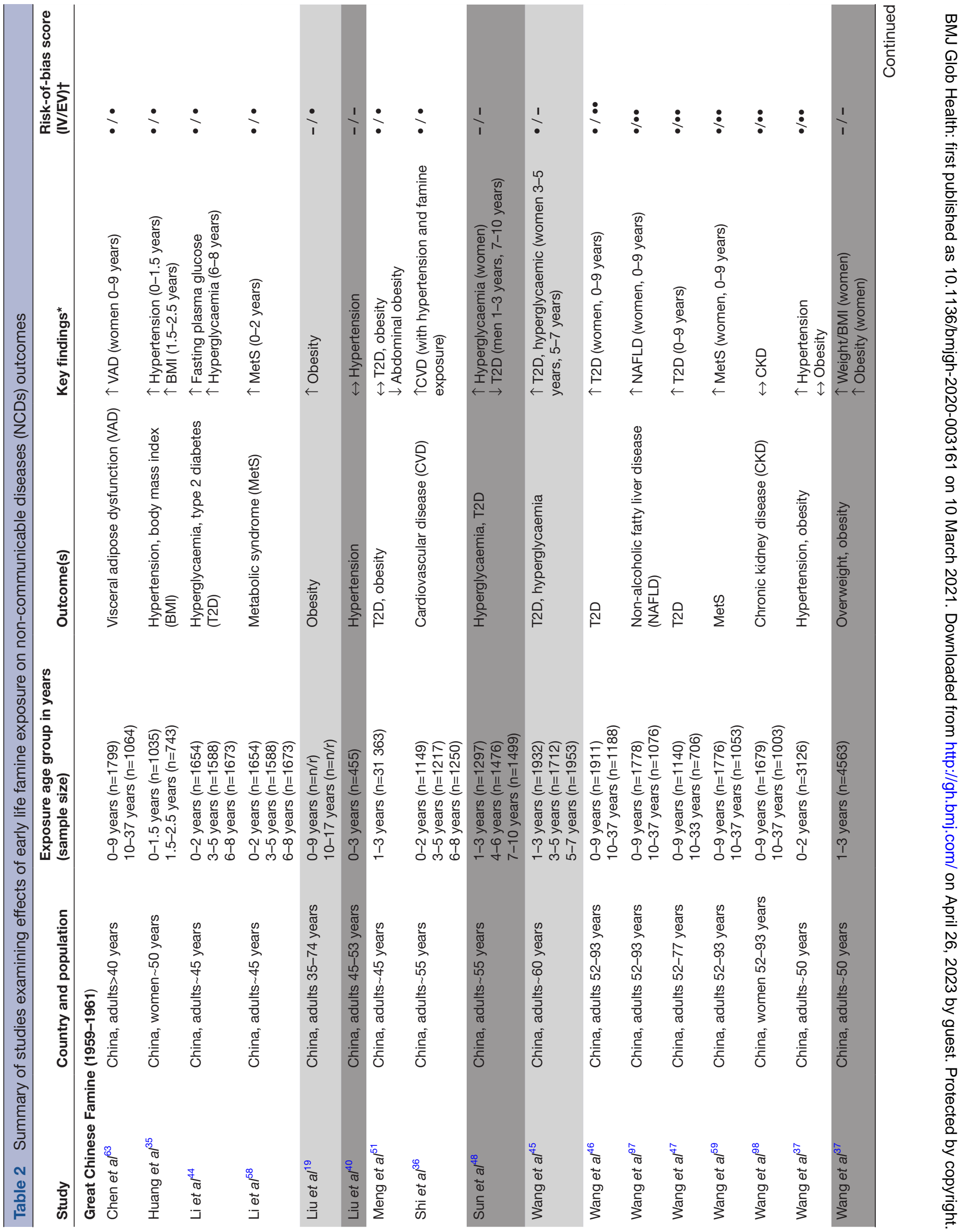




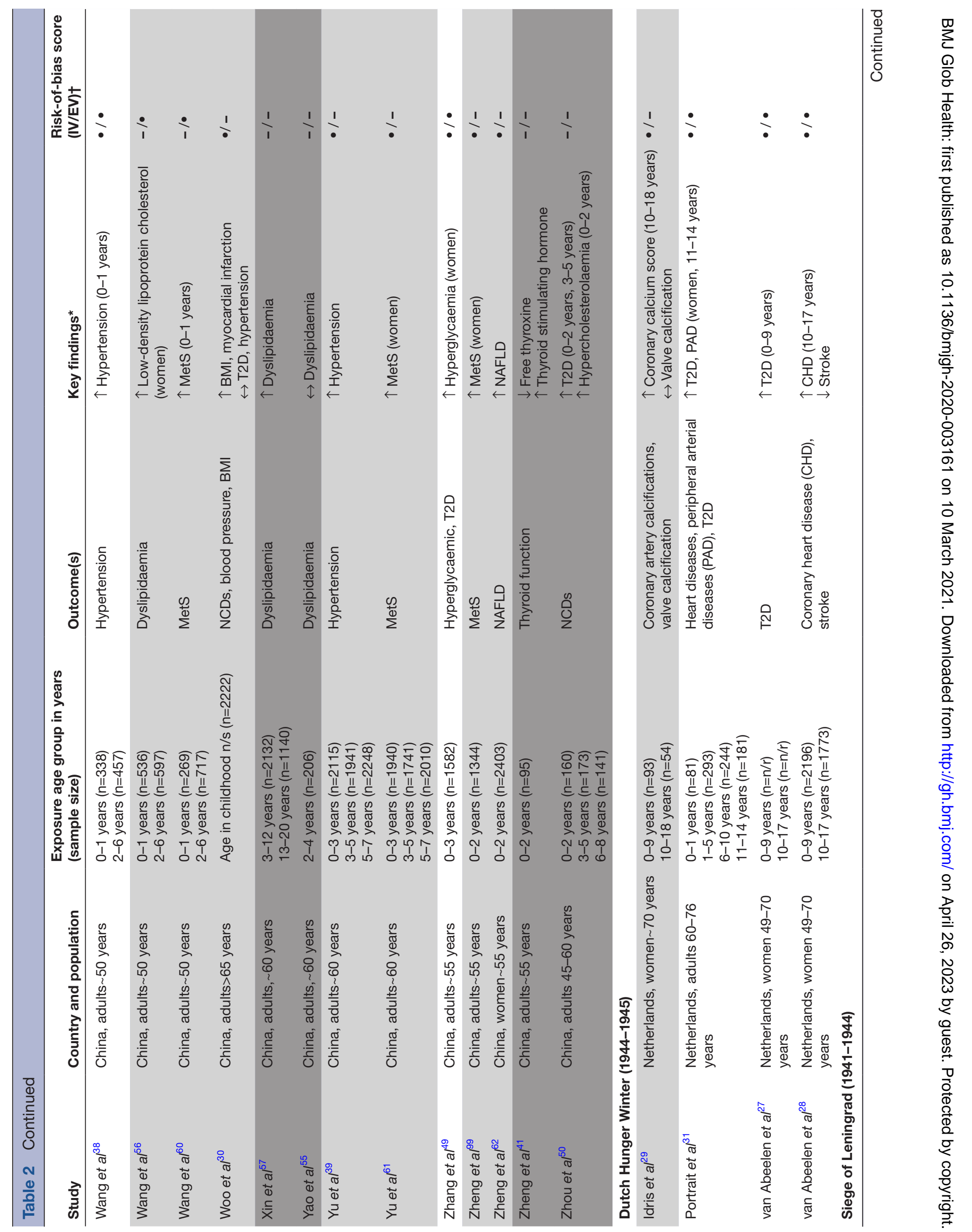




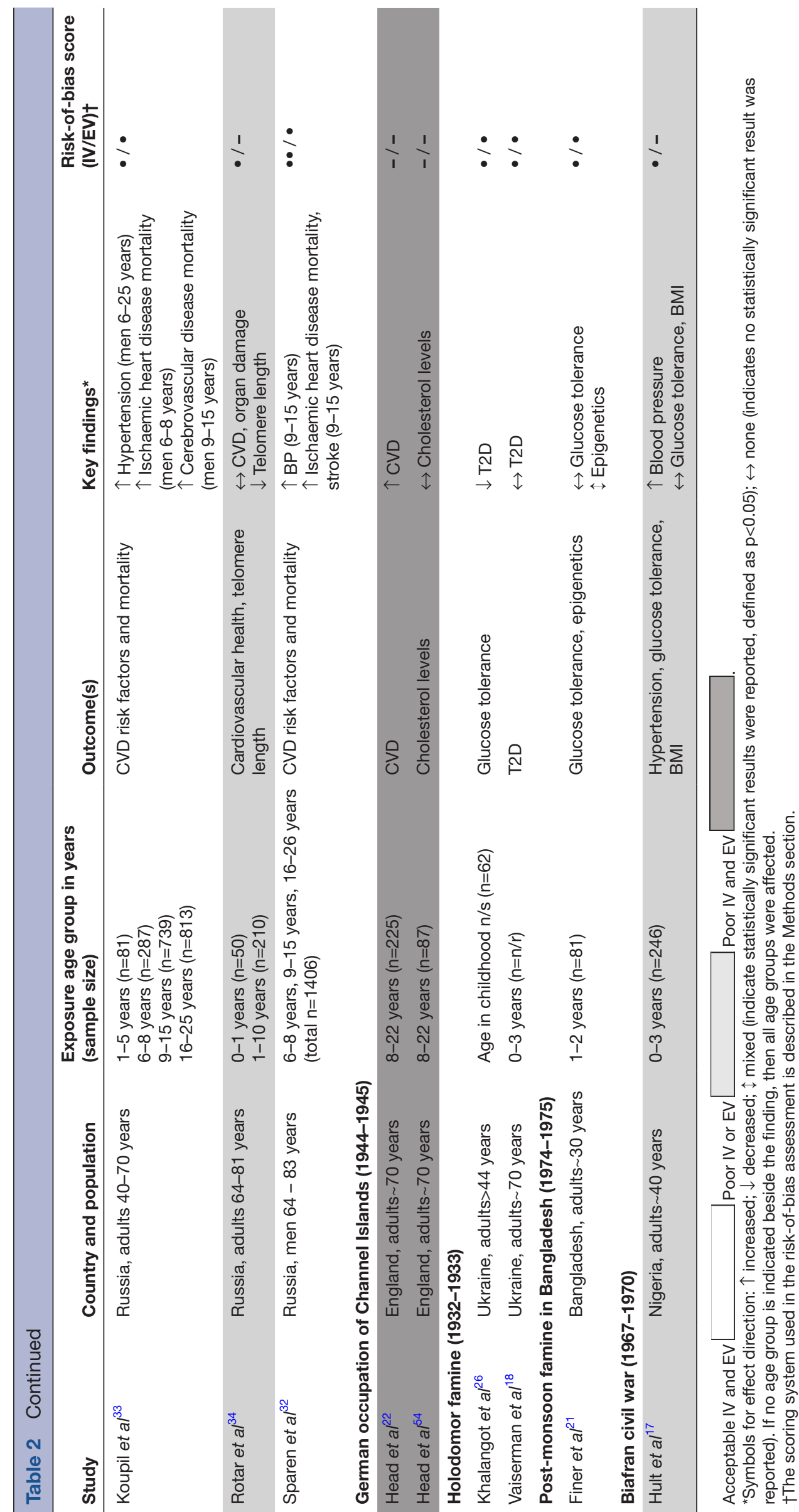

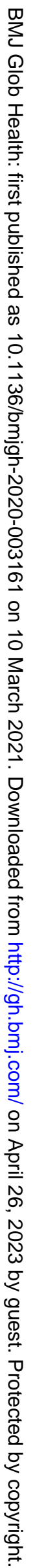



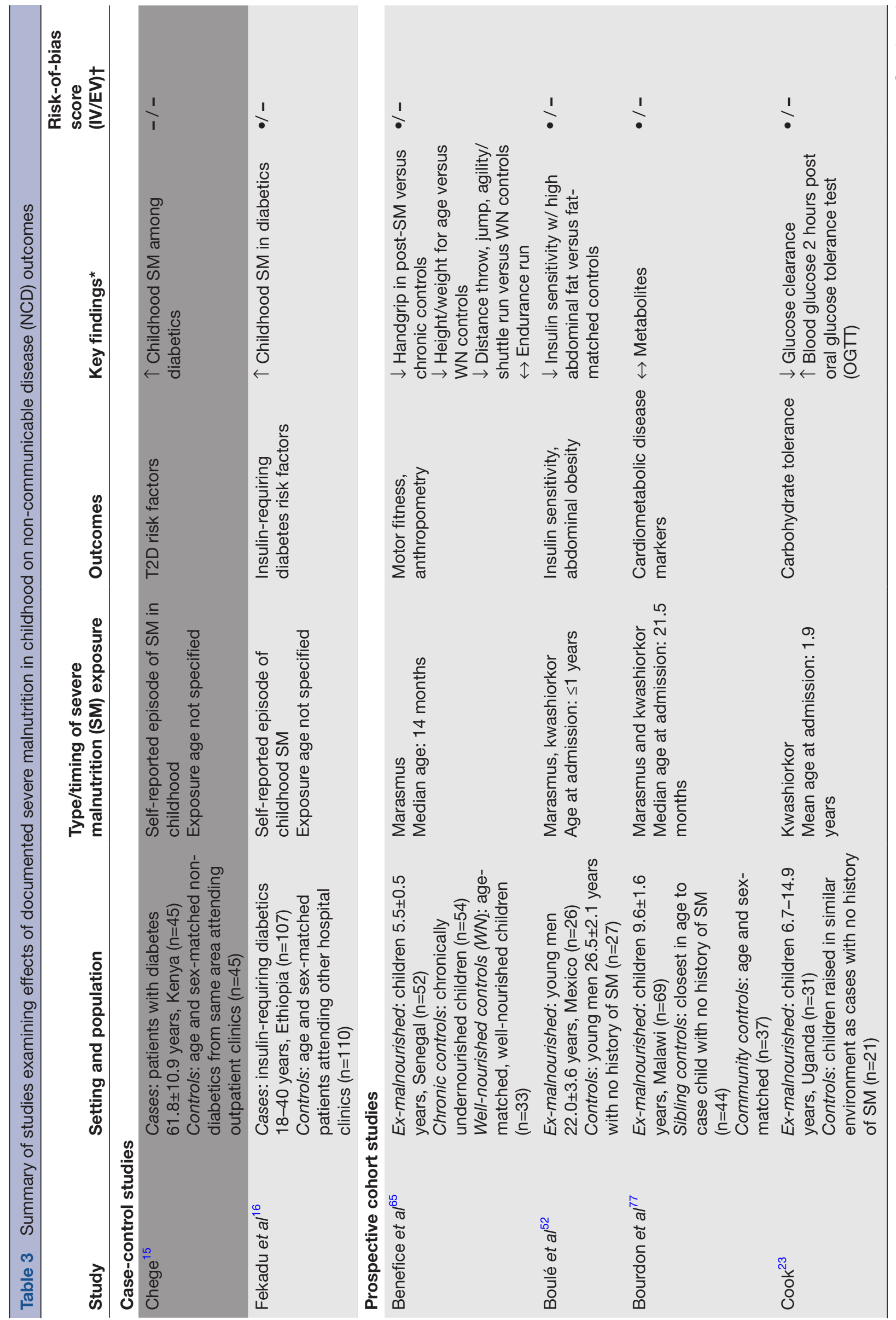


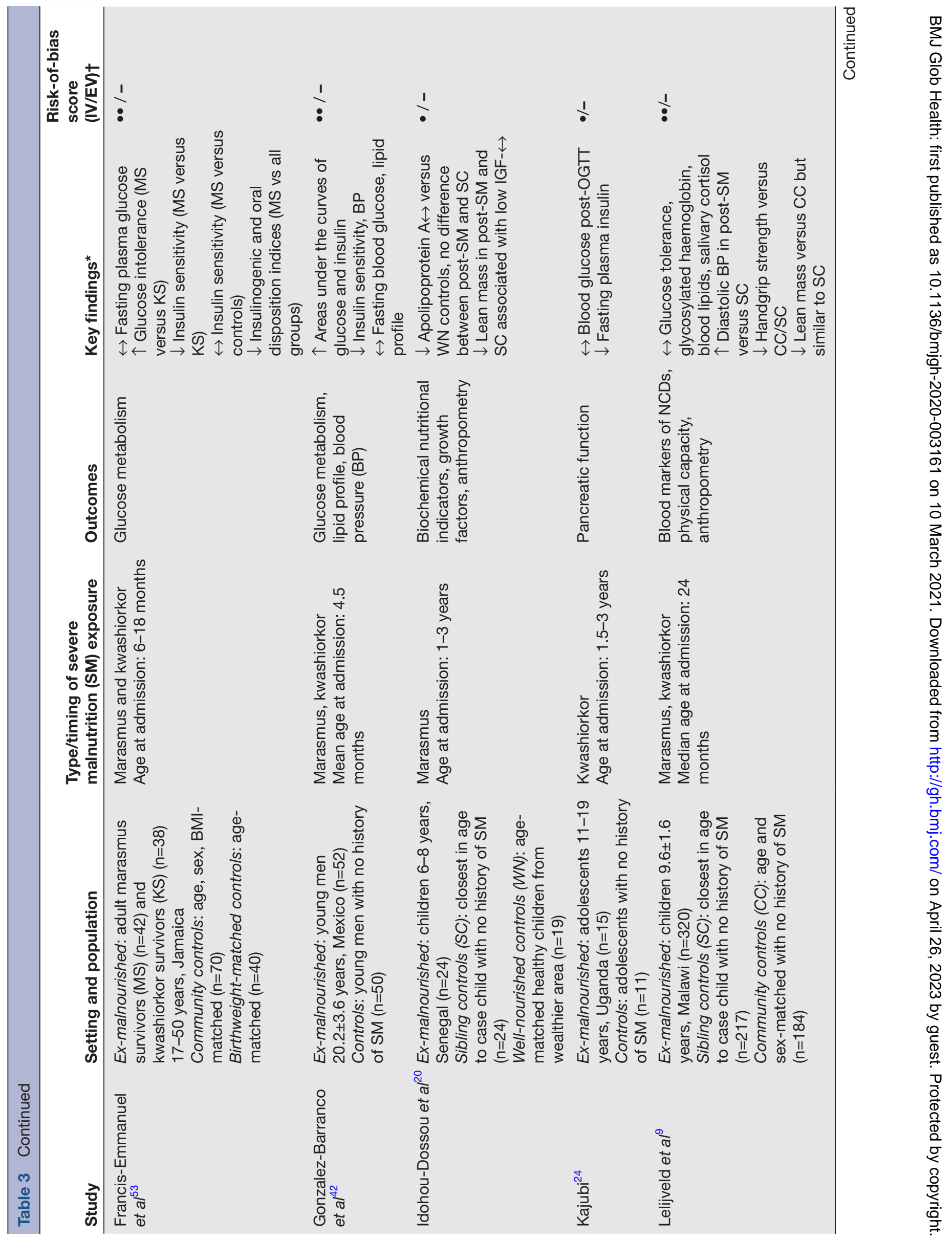




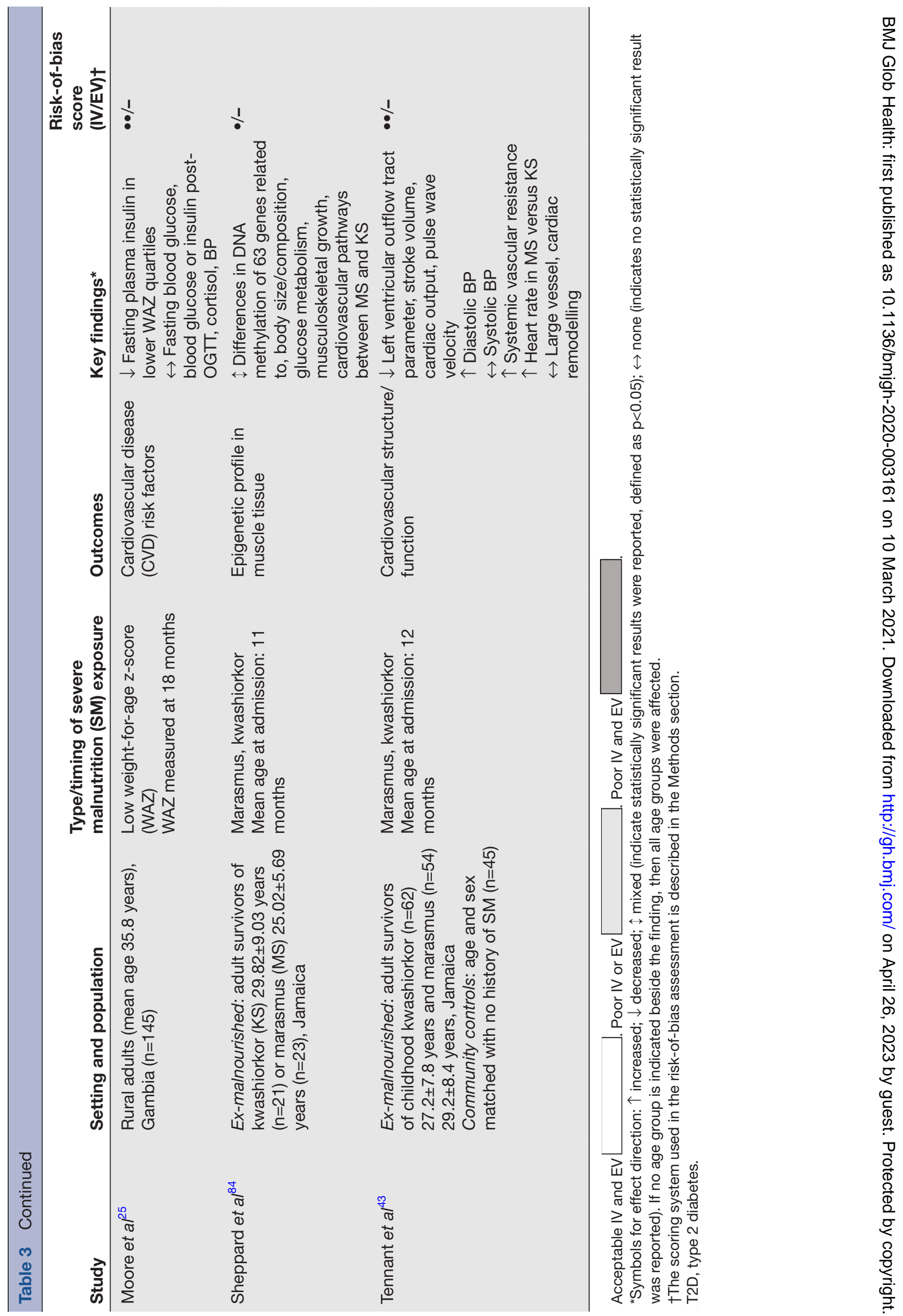


$(\mathrm{p}<0.0001)$ in survivors at $\sim 20$ years. ${ }^{42} 43$ Among Malawian survivors at $\sim 9$ years, $\mathrm{dBP}$ was higher than sibling controls $(\mathrm{d}=1.91 \mathrm{~mm} \mathrm{Hg}, \mathrm{p}=0.03) .{ }^{9}$ Meanwhile, a Gambian study showed no association between decreasing WAZ in the malnourished range in childhood and $\mathrm{sBP}$ or $\mathrm{dBP}$ at $\sim 36$ years in women. ${ }^{25}$

The single study that examined cardiovascular structure and function found reduced left ventricular outflow tract, stroke volume, cardiac output, and pulse wave velocity, together with increased systemic vascular resistance in survivors versus controls. ${ }^{43}$

\section{Glucose metabolism outcomes}

\section{Famine studies}

The evidence shows a positive association between childhood famine exposure and impaired glucose metabolism, with $2 / 15$ studies finding increased risk of hyperglycaemia and $7 / 15$ showing increased diabetes risk. ${ }^{2831} 44-50$ The five studies that stratified analyses by sex found increased risk of glucose metabolism disorders in women only. 3145464849

Increased risk of hyperglycaemia in famine-exposed women was found in two Chinese studies. Both found similarly increased risk as a result of early childhood famine exposure (0-3 years; OR 1.48 ; $95 \%$ CI 1.15 to $1.9^{48}$; OR $1.55 ; 95 \%$ CI 1.10 to $2.19^{49}$ ), with one study finding further associations with exposure in mid-childhood (4-6 years; OR 1.38 ; 95\% CI 1.06 to 1.79 ) and late childhood (7-10 years; OR 1.57; 95\% CI 1.25 to 1.98$).{ }^{48}{ }^{49}$ By contrast, one of these studies found a decreased risk of diabetes in men exposed to famine in early (OR 0.65; $95 \%$ CI 0.49 to 0.86 ) and late childhood (OR 0.74; $95 \%$ CI 0.56 to 0.98 ) compared with controls. ${ }^{48}$

Increased diabetes risk was found in seven studies from China and the Netherlands (5/7 and 2/7, respectively) after childhood famine exposure, ${ }^{28} 3144-4750$ with three studies reporting an effect in women only. ${ }^{31} 4546$ Increased diabetes risk was mainly observed among participants exposed to famine in early and late childhood (0-10 years); however, one Dutch study reported increased risk in the female adolescent exposure group (11-14 years) only. $^{31}$

Of the remaining six studies, five reported null findings and one reported a negative relationship between famine exposure and impaired glucose metabolism in adulthood. Studies from Bangladesh, Nigeria, China and Russia found no association between childhood famine exposure and impaired glucose metabolism when outcomes were assessed between $\sim 30$ and 80 years. ${ }^{1718214151}$ Finally, one study of Ukrainian famine survivors reported reduced diabetes risk in childhoodexposed participants (OR 0.063; 95\% CI 0.007 to 0.55 ) compared with unexposed controls. ${ }^{26}$

\section{Documented severe malnutrition studies}

The evidence indicates that severe childhood malnutrition is associated with impaired glucose metabolism in survivors, with $6 / 9$ studies reporting a positive association with diabetes, reduced insulin sensitivity, or glucose intolerance. ${ }^{15} 1623425253$ Notably, a Jamaican study that differentiated between survivors of marasmus and kwashiorkor reported greater fasting insulin, increased glucose intolerance, and reduced insulin sensitivity in adult marasmus survivors only. ${ }^{53}$ Conversely, a Ugandan study showed that glucose tolerance was impaired in kwashiorkor survivors compared with healthy controls. ${ }^{23}$ In a Mexican study, insulin sensitivity was reduced in survivors with high levels of abdominal fat even when matched to controls with similar levels of abdominal obesity; however, when matched for low amounts of abdominal fat, survivors and controls had similar insulin sensitivity. ${ }^{52}$ Severe childhood malnutrition was a risk factor for type 2 and insulinrequiring diabetes in case-control studies of patients with diabetes in Kenya and Ethiopia. ${ }^{15} 16$

The remaining 3/9 studies found no differences in glucose metabolism between severe malnutrition survivors and controls; however, these studies assessed outcomes in children, adolescents, and lean adults on a low-fat diet, respectively, which may have led to underestimation of the long-term effects of severe malnutrition. ${ }^{92425}$

\section{Lipid metabolism outcomes}

\section{Famine studies}

Of eight studies that reported on lipid metabolism outcomes, four reported no difference in lipid profiles between famine-exposed participants and controls. ${ }^{21415455}$ Three Chinese studies found increased risk of dyslipidaemia after childhood famine exposure between 0 and 12 years, with one also reporting an effect in the adolescent group (13-20 years). ${ }^{5056} 57$ A study of Leningrad Siege survivors found higher high-density lipoprotein (HDL) in exposed participants $(p=0.008)$ but no difference in triglycerides compared with controls. ${ }^{34}$ Only one Chinese study stratified analyses by sex and it found an increased risk of dyslipidaemia in women only. ${ }^{56}$

\section{Documented severe malnutrition studies}

Three studies of severe malnutrition survivors examined lipid metabolism, with two finding no differences between the lipid profiles of controls and survivors at $\sim 9$ years (Malawi) and $\sim 20$ years (Mexico), respectively. ${ }^{9} 42$ One study found reduced apolipoprotein A1 in Senegalese marasmus survivors compared with well-nourished controls $(\mathrm{p}<0.05)$ but no difference compared with sibling controls. ${ }^{20}$

\section{Metabolic syndrome outcomes Famine studies}

All five studies of metabolic syndrome (MetS) in Chinese famine survivors showed an increased risk in participants exposed between 0 and 9 years. ${ }^{58-62}$ Four studies stratified analyses by sex and found increased risk exclusively in women ${ }^{59-62}$ Another Chinese study used a different method to assess MetS-related outcomes called the 'visceral adiposity index' (VAI), a sex-specific equation 
based on waist circumference, BMI, and triglyceride and HDL levels. They found a positive association between childhood famine exposure (0-9 years) and VAI in women only. ${ }^{63}$

\section{Obesity-related outcomes \\ Famine studies}

Evidence on obesity-related outcomes in famine survivors showed mixed effects. Four Chinese studies reported increased BMI, obesity or overweight among those exposed to famine between 0 and 9 years and followed up in late adulthood. ${ }^{19} 303564$ Conversely, three studies found no association between famine exposure between 0 and 3 years and overweight, obesity, BMI or waist circumference. ${ }^{173741}$

\section{Documented severe malnutrition studies}

In contrast with famine survivors, evidence on anthropometric outcomes in severe malnutrition survivors indicates that they remain thinner than unexposed controls through childhood to adulthood. Of six studies, five reported that survivors had lower BMI, WFA, MUAC or WAZ than controls when measured as older children or adults. ${ }^{9} 20425265$ However, two studies noted that WFA and WAZ were lower in severe malnutrition survivors compared with well-nourished controls but observed no difference when compared with chronically malnourished or sibling controls, respectively. ${ }^{2065}$

Results for outcomes with $\leq 3$ studies reporting results can be found in online supplemental file 4, including NAFLD, physical capacity, chronic kidney disease, thyroid function, metabolomics, and epigenetic and genetic outcomes.

\section{DISCUSSION}

\section{Summary of main results}

We found evidence to support the hypothesis that exposure to severe malnutrition or famine during childhood increases long-term risk of cardiometabolic NCDs. The evidence was strongest for an association with CVD (myocardial infarction, coronary artery calcification, peripheral arterial disease, cerebrovascular disease, ischaemic heart disease, hypertension), impaired glucose metabolism (diabetes, hyperglycaemia) and MetS, while evidence for effects on lipid metabolism and obesity risk was less consistent. Where increased risk of NCDs in exposed groups was reported as an OR, effect sizes ranged from 1.11 to 5.50. Overall, these results suggest that childhood malnutrition may have a clinically, as well as statistically, significant effect on NCD risk in some survivors. Sex-specific differences were observed in some cohorts, with famine-exposed women at higher risk of glucose metabolism disorders and MetS than their male counterparts.

\section{Interpretation of findings}

Windows of developmental plasticity

Current literature suggests that developmental plasticity extends beyond prenatal life and that severe malnutrition in childhood exerts independent effects on NCD risk. Due to heterogeneity in exposure age across studies, it is difficult to conclude whether morbidity risk is higher among children exposed at specific ages. However, it appears that the window of plasticity could remain open beyond the first 1000 days of life, which is the focus of much current child health policy and programming.

Our results build on a narrative review of differences in cardiometabolic risk between marasmus and kwashiorkor survivors from Boyne et al (2017) by systematically identifying new evidence for an effect of severe malnutrition and famine exposure in childhood on NCD risk. ${ }^{11}$ Building on the DOHaD hypothesis, these findings indicate that severe childhood malnutrition may not only have serious implications for short-term morbidity and mortality but also for survivors' long-term health. This concept is described by Wells' (2018) 'capacity-load model of NCD risk', which proposes that individuals develop physiological traits during early life that give them the capacity to maintain homeostasis in metabolism and cardiovascular function when challenged by a metabolic load. ${ }^{66}$ Therefore, if postnatal malnutrition impairs development of metabolic capacity, then survivors are more vulnerable to NCDs in later life, especially in an increasingly obesogenic environment.

\section{Mechanistic links between severe malnutrition or famine in childhood and NCDS}

There is little mechanistic evidence linking severe malnutrition or famine in childhood and long-term NCD risk, with most studies speculating on mechanisms or extrapolating from findings on prenatal malnutrition. Commonly proposed mechanisms include:

\section{Growth acceleration}

There is strong evidence that periods of rapid postnatal weight gain increase obesity and CVD risk later in life, with observational and intervention studies showing that accelerated early growth is associated with later body fatness as well as increased BP, cholesterolaemia and insulin resistance ${ }^{67-71}$ Since rapid weight gain often follows episodes of severe childhood malnutrition, this may explain the increased CVD risk among those exposed to postnatal malnutrition followed by nutritional recovery. ${ }^{72}$ While the mechanisms linking rapid weight gain with NCD risk are not fully understood, the evidence is strongest for increased visceral adiposity as the key causal factor in CVD and diabetes. ${ }^{73-75}$

\section{Body composition in later life}

Endocrine changes caused by malnutrition may influence body composition in adult survivors and affect their NCD risk. ${ }^{11}$ Reduced growth factors (eg, IGF-1) and insulin, along with higher cortisol levels, may be conducive to stunting, reduced muscle mass, and a tendency towards obesity with high calorie intake. ${ }^{76}$ In studies of older children who experienced severe malnutrition in early life, survivors had less lean mass and more stunting compared with community controls, which was associated with low IGF-1. ${ }^{90} 77$ This phenotype may increase 
NCD risk as skeletal muscle is the major site of insulininduced glucose uptake and therefore protects against insulin resistance and MetS. ${ }^{78} 79$

\section{Impaired pancreatic function}

Animal studies have shown that postnatal malnutrition negatively impacts pancreatic $\beta$-cell function. ${ }^{80} 81$ When malnutrition was induced in rats during lactation and the postweaning period using a low-protein diet, there were negative effects on insulin secretion leading to impaired glucose tolerance. On nutritional rehabilitation, the deleterious effects were reversed in the lactation-exposed group but not in the postweaning group, suggesting that postnatal malnutrition can permanently alter pancreatic function and lead to glucose metabolism disorders. ${ }^{80}$

\section{Altered hypothalamic-pituitary-adrenocortical (HPA) axis}

Exposure to stressors in utero and during childhood may alter the set-point of the HPA axis as an adaptation to cope with an anticipated high-stress environment in later life. ${ }^{82}$ However, these changes in neuroendocrine mediators of the stress response may predispose to metabolic disease when the adult environment is mismatched for these adaptations as excess glucocorticoids have been associated with hypertension and glucose intolerance. ${ }^{83}$

\section{Epigenetic changes}

While literature on epigenetic effects of early-life malnutrition on NCD risk largely focuses on the antenatal period, postnatal malnutrition may also cause epigenetic changes that contribute to future cardiometabolic disease risk. ${ }^{21} 8485$ If epigenetic plasticity extends into postnatal life, then this may provide the mechanistic link between early-life malnutrition and later disease by 'programming' an adverse metabolic phenotype. ${ }^{86} 87$ However, epigenetic studies on the effects of childhood malnutrition are limited, and this theory requires further supporting evidence.

\section{Sex-specific effects}

Women exposed to famine in childhood appear to be at higher risk of glucose metabolism disorders and MetS than famine-exposed men. This finding is supported by a recent meta-analysis examining the effect of earlylife famine exposure on risk of MetS in adulthood that included 39 studies $(\mathrm{n}=81$ 504). Compared with a nonexposed group, early-life famine exposure significantly increased the risk of MetS in women only. ${ }^{88}$ However, most studies were conducted in China where families may have preferentially allocated food and other resources to sons at the expense of daughters during the famine due to a culture of 'son preference'. ${ }^{89}$ Malnutrition severity may thus explain increased NCD risk in women ${ }^{89}$ While hypothetically this would select for the healthiest female survivors, it would also improve the average welfare of males, leading to better long-term health. ${ }^{89}$ Another explanation might be healthy survivor effect in boys as a recent review found that they are biologically more vulnerable to malnutrition and potentially only the healthiest survived. ${ }^{90}$

\section{Review limitations and strengths}

We acknowledge several limitations. Due to our broad scope, there was extensive clinical and methodological heterogeneity between studies, rendering it difficult to directly compare study findings. As all studies were observational, associations cannot be interpreted as causal. This makes it difficult to disentangle the effects of fetal and postnatal malnutrition. Few studies controlled for effects of foetal malnutrition as the proxy measure of birth weight was rarely available; however, four studies showed independent effects of postnatal malnutrition on NCD risk after controlling for birth weight. ${ }^{22} 425253$ Inadequately controlled age effects are another important confounder as most famine studies used birthdate to determine famine exposure. This was primarily an issue in Chinese studies as there were no truly unexposed areas during the Chinese famine, rendering it difficult to make comparisons with age-matched controls. ${ }^{48}$ Because there was no overlap in the birth years of exposed and non-exposed participants, age adjustment in regression models alone will have no impact on risk estimate calculations. ${ }^{91}$ Without an age-matched or age-balanced control group, age differences between groups may explain many of the effects on NCD outcomes attributed to famine exposure because ageing is a risk factor for NCDs and childhood-exposed groups were older than controls born post famine. ${ }^{91} 92$

Another limitation is the small sample size in some studies; thus, the children included may not represent the wider affected/at-risk population and chance observations are possible. We also note the risk of selection and information bias. Because severe childhood malnutrition is associated with high mortality, participants may represent the healthiest survivors and any effects observed in these populations may underestimate long-term health impacts of severe malnutrition. ${ }^{9}{ }^{93}$ Misclassification of famine exposure status is an important source of information bias. Most studies assigned exposure status and severity based on birth date and place relative to famine years and regions of excess mortality. This may have resulted in misclassification of participants into incorrect exposure groups because individual exposure data were not available; participants may have been exposed to varying degrees of famine severity or even entirely protected for circumstantial reasons.

Finally, we recognise the currently limited data sources on this topic; although we identified an important number of individual papers, many were from the same famine event and some had high risk of bias. However, even when studies with higher risk of bias were discounted from our analysis, we found that most studies from the Great Chinese Famine, Dutch Hunger Winter and Siege of Leningrad (the famine events for which there were $>2$ available studies) showed a positive association between famine exposure and NCD outcomes. Therefore, our 
conclusions regarding the potential relationship between famine exposure and NCDs remain valid and all studies were included in the results so as to present a complete overview of available literature. We hope that future research in different settings might add further weight to our findings.

Our review has several strengths. To our knowledge, this is the only systematic review on this topic. It examines a highly topical subject; COVID-19 threatens to trigger food crises and famines worldwide, putting great numbers of children at risk of severe malnutrition. ${ }^{94-96}$ The resulting potential increase in NCDs risks putting a major burden on already overstretched health systems in LMICs in coming decades. Finally, while all studies were observational, there was consistency in findings, strength of associations, biological plausibility, temporal progression between exposure and outcomes, and coherence between epidemiological and laboratory findings. ${ }^{80} 81$

\section{Implications of findings and future research}

If postnatal malnutrition influences long-term NCD risk as our results suggest, this is of global public health significance given the growing NCD epidemic in LMICs where there remains a large burden of severe childhood malnutrition. ${ }^{3}$ Prevention of severe malnutrition should be prioritised as no child should have to suffer the short-term or long-term effects of malnutrition. While short-term mortality and morbidity are widely recognised outcomes of malnutrition, we hope that the case for prevention will be further strengthened once policymakers and funders appreciate the long-term sequelae highlighted in our review.

With over $80 \%$ of premature NCD-related deaths occurring in LMICs, where health systems already struggle with this massive disease burden, the need for interventions to prevent NCDs among severe malnutrition survivors is urgent. Our review highlights the limited evidence relevant to LMIC contexts, where severe malnutrition remains a threat to public health. Many of the highest quality studies we identified were conducted in settings where famine events were short lived and therefore may underestimate the effects of severe malnutrition in some contemporary contexts where malnutrition is endemic. There is a need for more high-quality studies in a wider range of contemporary LMIC settings to explore the potential links between severe malnutrition and NCDs.

There is reasonable strength and consistency in the findings and biological plausibility to indicate an association between severe malnutrition or famine exposure and increased NCD risk. However, the precise mechanisms underlying this association remain largely unclear. For instance, how do long-term outcomes differ by duration, intensity, and age at which a child experiences malnutrition and what are the biological processes leading to long-term adverse effects. Research in this area will be essential to inform policy and programming around prevention and management strategies for severe childhood malnutrition that promote long-term health in survivors as well as strategies to mitigate NCD risk among famine survivors. Recent predictions of major hunger following the COVID-19 pandemic make our review particularly timely. ${ }^{94} 95$ Taking action to prevent and appropriately treat this hunger is not only vital to save child lives, but also matters for NCD prevalence in decades to come.

\section{CONCLUSION}

Our review indicates that severe malnutrition or famine exposure in childhood is associated with increased NCD risk later in life. The evidence on CVD, impaired glucose metabolism and MetS consistently shows deleterious effects of postnatal malnutrition on these chronic disease outcomes. Evidence for effects on lipid metabolism and obesity risk is less consistent.

Given that many countries with large burdens of child malnutrition also face NCD epidemics, understanding associations between severe childhood malnutrition and chronic diseases has major implications for preventing long-term morbidity and mortality. Increased global hunger resulting from the COVID-19 pandemic makes this link more important than ever. Efforts must be made to prevent and appropriately treat child malnutrition: not only to avoid short-term mortality, but to avoid escalating an already overwhelming NCD burden in decades to come. Better evidence is required from contemporary LMIC contexts where severe malnutrition may be inflicting long-lasting damage on public health.

\section{Author affiliations}

${ }^{1}$ Population Health, London School of Hygiene \& Tropical Medicine, London, UK ${ }^{2}$ Division of Human Nutrition and Health, Wageningen University, Wageningen, Netherlands

${ }^{3}$ Department of Psychiatry, Jimma University, Jimma, Ethiopia

${ }^{4}$ Emergency Nutrition Network, Kidlington, UK

${ }^{5}$ Caribbean Institute for Health Research, University of the West Indies, Kingston, Jamaica

${ }^{6}$ Department of Pediatrics and Child Health, Jimma University, Jimma, Ethiopia ${ }^{7}$ Armauer Hansen Research Institute, Addis Ababa, Ethiopia

${ }^{8}$ Population Health, London School of Hygiene and Tropical Medicine, London, UK

Twitter Marko Kerac @GlobalHealthNut

Contributors MK and KG conceived the study design. KG carried out the main research work on this review, including running the searches, extracting data, assessing the risk of bias, and writing up this manuscript with input from MK, $\mathrm{NL}, \mathrm{DT}, \mathrm{TG}, \mathrm{MA}, \mathrm{MB}, \mathrm{AA}$ and $\mathrm{GBG}$. All authors have read and approved the final manuscript.

Funding This study was funded by Medical Research Council (MR/T008628/1).

Competing interests None declared.

Patient consent for publication Not required.

Provenance and peer review Not commissioned; externally peer reviewed.

Data availability statement All data relevant to the study are included in the article or uploaded as supplementary information. All data were collected from previously published studies.

Supplemental material This content has been supplied by the author(s). It has not been vetted by BMJ Publishing Group Limited (BMJ) and may not have been peer-reviewed. Any opinions or recommendations discussed are solely those of the author(s) and are not endorsed by BMJ. BMJ disclaims all liability and responsibility arising from any reliance placed on the content. Where the content includes any translated material, BMJ does not warrant the accuracy and reliability 
of the translations (including but not limited to local regulations, clinical guidelines, terminology, drug names and drug dosages), and is not responsible for any error and/or omissions arising from translation and adaptation or otherwise.

Open access This is an open access article distributed in accordance with the Creative Commons Attribution 4.0 Unported (CC BY 4.0) license, which permits others to copy, redistribute, remix, transform and build upon this work for any purpose, provided the original work is properly cited, a link to the licence is given, and indication of whether changes were made. See: https://creativecommons.org/ licenses/by/4.0/.

\section{ORCID iDs}

Kelsey Grey http://orcid.org/0000-0002-8980-9396

Marko Kerac http://orcid.org/0000-0002-3745-7317

\section{REFERENCES}

1 United Nations Children's Fund (UNICEF), World Health Organization, International Bank for Reconstruction and Development/The World Bank. Levels and trends in child malnutrition: key findings of the 2020 edition of the joint child malnutrition estimates. World Health Organization, 2020.

2 Black RE, Victora CG, Walker SP, et al. Maternal and child undernutrition and overweight in low-income and middle-income countries. Lancet 2013;382:427-51.

3 World Health Organization. Global status report on noncommunicable diseases 2014. World Health Organization, 2014.

4 Fall CHD. Fetal programming and the risk of noncommunicable disease. Indian J Pediatr 2013;80:S13-20.

5 Bhutta ZA, Berkley JA, Bandsma RHJ, et al. Severe childhood malnutrition. Nat Rev Dis Primers 2017;3:17067.

6 Liu L, Oza S, Hogan D, et al. Global, regional, and national causes of under-5 mortality in 2000-15: an updated systematic analysis with implications for the sustainable development goals. The Lancet 2016;388:3027-35.

7 WHO. Guideline: assessing and managing children at primary health-care facilities to prevent overweight and obesity in the context of the double burden of malnutrition. updates for the integrated management of childhood illness (IMCl). World Health Organization, 2017.

8 United Nations. Sustainable development goal 3, 2015. Available: https://sustainabledevelopment.un.org/sdg3

9 Lelijveld N, Seal A, Wells JC, et al. Chronic disease outcomes after severe acute malnutrition in Malawian children (ChroSAM): a cohort study. Lancet Glob Health 2016;4:e654-62.

10 Gunnell D, Whitley E, Upton MN, et al. Associations of height, leg length, and lung function with cardiovascular risk factors in the Midspan family study. J Epidemiol Community Health 2003:57:141-6.

11 Boyne MS, Francis-Emmanuel P, Tennant IA, et al. Cardiometabolic risk in marasmus and kwashiorkor survivors. In: Preedy V, Patel VB, eds. Handbook of famine, starvation, and nutrient deprivation: from biology to policy. Springer International Publishing, 2017: 1-23.

12 Moher D, Liberati A, Tetzlaff J, et al. Preferred reporting items for systematic reviews and meta-analyses: the PRISMA statement. PLoS Med 2009;6:e1000097.

13 de Onis M, Branca F. Childhood stunting: a global perspective. Matern Child Nutr 2016;12(Suppl 1):12-26.

14 National Institute for Health and Clinical Excellence. Quality appraisal checklist - quantitative studies reporting correlations and associations. In: Methods for the development of NICE public health guidance (Third Edition), 2012. https://www.nice.org.uk/process/ pmg4/chapter/appendix-g-quality-appraisal-checklist-quantitativestudies-reporting-correlations-and\#footnote_16

15 Chege MP. Risk factors for type 2 diabetes mellitus among patients attending a rural Kenyan Hospital. Afr J Prim Health Care Fam Med 2010;2.

16 Fekadu S, Yigzaw M, Alemu S, et al. Insulin-requiring diabetes in Ethiopia: associations with poverty, early undernutrition and anthropometric disproportion. Eur J Clin Nutr 2010;64:1192-8.

17 Hult M, Tornhammar P, Ueda P, et al. Hypertension, diabetes and overweight: looming legacies of the Biafran famine. PLoS One 2010;5:e13582.

18 Vaiserman A, Khalangot MD, Strele I, et al. Early-Life exposure to the Ukraine famine of 1933 and type 2 diabetes in adulthood. Nova Science Publishers Inc, 2013.

19 Liu L, Pang ZC, Sun JP, et al. Exposure to famine in early life and the risk of obesity in adulthood in Qingdao: evidence from the 19591961 Chinese famine. Nutr Metab Cardiovasc Dis 2017;27:154-60.
20 Idohou-Dossou N, Wade S, Guiro AT, et al. Nutritional status of preschool Senegalese children: long-term effects of early severe malnutrition. Br J Nutr 2003;90:1123-32.

21 Finer S, lqbal MS, Lowe R, et al. Is famine exposure during developmental life in rural Bangladesh associated with a metabolic and epigenetic signature in young adulthood? A historical cohort study. BMJ Open 2016;6:e011768.

22 Head RF, Gilthorpe MS, Byrom A, et al. Cardiovascular disease in a cohort exposed to the 1940-45 channel islands occupation. BMC Public Health 2008;8:303.

23 Cook GC. Glucose and starch tolerance after recovery from kwashiorkor. Metabolism 1968;17:1073-83.

24 Kajubi SK. The endocrine pancreas after kwashiorkor. Am J Clin Nutr 1972;25:1140-2.

25 Moore SE, Halsall I, Howarth D, et al. Glucose, insulin and lipid metabolism in rural Gambians exposed to early malnutrition. Diabet Med 2001;18:646-53.

26 Khalangot MD, Kovtun VA, Okhrimenko NV, et al. Glucose tolerance testing and anthropometric comparisons among rural residents of Kyiv region: investigating the possible effect of childhood Starvation-A community-based study. Nutr Metab Insights 2017;10:1178638817741281.

27 van Abeelen AFM, Elias SG, Bossuyt PMM, et al. Cardiovascular consequences of famine in the young. Eur Heart J 2012;33:538-45.

28 van Abeelen AFM, Elias SG, Bossuyt PMM, et al. Famine exposure in the young and the risk of type 2 diabetes in adulthood. Diabetes 2012;61:2255-60.

29 Idris NS, Uiterwaal CSPM, van der Schouw YT, et al. Famine in childhood and postmenopausal coronary artery calcification: a cohort study. BMJ Open 2013;3:e003818.

30 Woo J, Leung JCS, Wong SYS. Impact of childhood experience of famine on late life health. J Nutr Health Aging 2010;14:91-5.

31 Portrait F, Teeuwiszen E, Deeg D. Early life undernutrition and chronic diseases at older ages: the effects of the Dutch famine on cardiovascular diseases and diabetes. Soc Sci Med 2011;73:711-8.

32 Sparén $\mathrm{P}$, Vågerö $\mathrm{D}$, Shestov $\mathrm{DB}$, et al. Long term mortality after severe starvation during the siege of Leningrad: prospective cohort study. BMJ 2004;328:11.

33 Koupil I, Shestov DB, Sparén P, et al. Blood pressure, hypertension and mortality from circulatory disease in men and women who survived the siege of Leningrad. Eur J Epidemiol 2007;22:223-34.

34 Rotar O, Moguchaia E, Boyarinova M, et al. Seventy years after the siege of Leningrad: does early life famine still affect cardiovascular risk and aging? J Hypertens 2015;33:1772-9.

35 Huang C, Li Z, Wang M, et al. Early life exposure to the 19591961 Chinese famine has long-term health consequences. J Nutr 2010;140:1874-8.

36 Shi Z, Nicholls SJ, Taylor AW, et al. Early life exposure to Chinese famine modifies the association between hypertension and cardiovascular disease. J Hypertens 2018;36:54.

37 Wang P-X, Wang J-J, Lei Y-X, et al. Impact of fetal and infant exposure to the Chinese great famine on the risk of hypertension in adulthood. PLoS One 2012;7:e49720.

38 Wang Z, Li C, Yang Z, et al. Infant exposure to Chinese famine increased the risk of hypertension in adulthood: results from the China health and retirement longitudinal study. BMC Public Health 2016;16:435.

39 Yu C, Wang J, Li Y, et al. Exposure to the Chinese famine in early life and hypertension prevalence risk in adults. J Hypertens 2017;35:63.

40 Liu L, Xu X, Zeng H, et al. Increase in the prevalence of hypertension among adults exposed to the great Chinese famine during early life. Environ Health Prev Med 2017;22:64.

41 Zheng X, Long J, Ren W, et al. Exposure to the Chinese famine in early life and the thyroid function and nodules in adulthood. Endocr Pract 2019;25:598-604.

42 González-Barranco J, Ríos-Torres JM, Castillo-Martínez L, et al. Effect of malnutrition during the first year of life on adult plasma insulin and glucose tolerance. Metabolism 2003;52:1005-11.

43 Tennant IA, Barnett AT, Thompson DS, et al. Impaired cardiovascular structure and function in adult survivors of severe acute malnutrition. Hypertension 2014;64:664-71.

$44 \mathrm{Li} \mathrm{Y,} \mathrm{He} \mathrm{Y,} \mathrm{Qi} \mathrm{L,} \mathrm{et} \mathrm{al.} \mathrm{Exposure} \mathrm{to} \mathrm{the} \mathrm{Chinese} \mathrm{famine} \mathrm{in} \mathrm{early} \mathrm{life} \mathrm{and}$ the risk of hyperglycemia and type 2 diabetes in adulthood. Diabetes 2010:59:2400-6.

45 Wang J, Li Y, Han X, et al. Exposure to the Chinese famine in childhood increases type 2 diabetes risk in adults. $J$ Nutr 2016;146:2289-95.

46 Wang N, Wang X, Han B, et al. Is exposure to famine in childhood and economic development in adulthood associated with diabetes? J Clin Endocrinol Metab 2015;100:4514-23. 
47 Wang N, Cheng J, Han B, et al. Exposure to severe famine in the prenatal or postnatal period and the development of diabetes in adulthood: an observational study. Diabetologia 2017;60:262-9.

48 Sun Y, Zhang L, Duan W, et al. Association between famine exposure in early life and type 2 diabetes mellitus and hyperglycemia in adulthood: results from the China health and retirement longitudinal study (CHARLS). J Diabetes 2018;10:724-33.

49 Zhang $\mathrm{Y}$, Liu X, Wang M, et al. Risk of hyperglycemia and diabetes after early-life famine exposure: a cross-sectional survey in northeastern China. Int J Environ Res Public Health 2018;15:1125.

50 Zhou J, Sheng J, Fan Y. The effect of Chinese famine exposure in early life on dietary patterns and chronic diseases of adults. Public Health Nutr 2019;22:603-13.

51 Meng R, Lv J, Yu C, et al. Prenatal famine exposure, adulthood obesity patterns and risk of type 2 diabetes. Int $J$ Epidemiol 2018;47:399-408.

52 Boulé NG, Tremblay A, Gonzalez-Barranco J, et al. Insulin resistance and abdominal adiposity in young men with documented malnutrition during the first year of life. Int J Obes Relat Metab Disord 2003;27:598-604.

53 Francis-Emmanuel PM, Thompson DS, Barnett AT, et al. Glucose metabolism in adult survivors of severe acute malnutrition. $J$ Clin Endocrinol Metab 2014;99:2233-40.

54 Head RF, Gilthorpe MS, Ellison GTH. Cholesterol levels in later life amongst UK channel Islanders exposed to the 1940-45 German occupation as children, adolescents and young adults. Nutr Health 2009;20:91-105.

$55 \mathrm{Yao} \mathrm{H}, \mathrm{Li} \mathrm{L}$. Famine exposure during the fetal period increased the risk of dyslipidemia in female adults. Lipids 2019;54:301-9.

56 Wang Z, Li C, Yang Z, et al. Fetal and infant exposure to severe Chinese famine increases the risk of adult dyslipidemia: results from the China health and retirement longitudinal study. BMC Public Health 2017;17:488.

57 Xin X, Wang W, Xu H, et al. Exposure to Chinese famine in early life and the risk of dyslipidemia in adulthood. Eur J Nutr 2019;58:391-8.

$58 \mathrm{Li}$ Y, Jaddoe VW, Qi L, et al. Exposure to the Chinese famine in early life and the risk of metabolic syndrome in adulthood. Diabetes Care 2011;34:1014-8.

59 Wang $N$, Wang $X$, Li Q, et al. The famine exposure in early life and metabolic syndrome in adulthood. Clin Nutr 2017;36:253-9.

60 Wang Z, Zou Z, Wang S, et al. Chinese famine exposure in infancy and metabolic syndrome in adulthood: results from the China health and retirement longitudinal study. Eur J Clin Nutr 2019;73:724-32.

61 Yu C, Wang J, Wang F, et al. Victims of Chinese famine in early life have increased risk of metabolic syndrome in adulthood. Nutrition 2018;53:20-5.

62 Zheng X, Wang Y, Ren W, et al. Risk of metabolic syndrome in adults exposed to the great Chinese famine during the fetal life and early childhood. Eur J Clin Nutr 2012;66:231-6.

63 Chen C, Zhao L, Ning Z, et al. Famine exposure in early life is associated with visceral adipose dysfunction in adult females. Eur $\mathrm{J}$ Nutr 2019;58:1625-33.

64 Wang $\mathrm{Y}$, Wang $\mathrm{X}$, Kong $\mathrm{Y}$, et al. The great Chinese famine leads to shorter and overweight females in Chongqing Chinese population after 50 years. Obesity 2010;18:588-92.

65 Bénéfice $\mathrm{E}$, Fouére T, Malina RM. Early nutritional history and motor performance of Senegalese children, 4-6 years of age. Ann Hum Biol 1999;26:443-55.

66 Wells JCK. The capacity-load model of non-communicable disease risk: understanding the effects of child malnutrition, ethnicity and the social determinants of health. Eur J Clin Nutr 2018;72:688-97.

67 Baird J, Fisher D, Lucas P, et al. Being big or growing fast: systematic review of size and growth in infancy and later obesity. BMJ 2005;331:929.

68 Ong KK, Loos RJF. Rapid infancy weight gain and subsequent obesity: systematic reviews and hopeful suggestions. Acta Paediatr 2006;95:904-8.

69 Stettler N. Nature and strength of epidemiological evidence for origins of childhood and adulthood obesity in the first year of life. Int $J$ Obes 2007;31:1035-43.

70 Ekelund U, Ong KK, Linné Y, et al. Association of weight gain in infancy and early childhood with metabolic risk in young adults. $J$ Clin Endocrinol Metab 2007;92:98-103.

71 Singhal A, Lucas A. Early origins of cardiovascular disease: is there a unifying hypothesis? The Lancet 2004;363:1642-5.

72 O'Sullivan NP, Lelijveld N, Rutishauser-Perera A, et al. Follow-up between 6 and 24 months after discharge from treatment for severe acute malnutrition in children aged 6-59 months: a systematic review. PLoS One 2018;13:e0202053.
73 Durmus B, Mook-Kanamori DO, Holzhauer S, et al. Growth in foetal life and infancy is associated with abdominal adiposity at the age of 2 years: the generation R study. Clin Endocrinol 2010;72:633-40.

74 Demerath EW, Reed D, Choh AC, et al. Rapid postnatal weight gain and visceral adiposity in adulthood: the Fels longitudinal study. Obesity 2009;17:2060-6.

75 Ibáñez L, Suárez L, Lopez-Bermejo A, et al. Early development of visceral fat excess after spontaneous catch-up growth in children with low birth weight. J Clin Endocrinol Metab 2008;93:925-8.

76 Sawaya AL, Martins PA, Grillo LP, et al. Long-term effects of early malnutrition on body weight regulation. Nutr Rev 2004;62:S127-33.

77 Bourdon C, Lelijveld N, Thompson D, et al. Metabolomics in plasma of Malawian children 7 years after surviving severe acute malnutrition: "ChroSAM" a cohort study. EBioMedicine 2019:45:464-72.

78 Srikanthan P, Karlamangla AS. Relative muscle mass is inversely associated with insulin resistance and prediabetes. Findings from the third National health and nutrition examination survey. J Clin Endocrinol Metab 2011;96:2898-903.

79 Kim K, Park SM. Association of muscle mass and fat mass with insulin resistance and the prevalence of metabolic syndrome in Korean adults: a cross-sectional study. Sci Rep 2018;8:1-8.

80 Miñana-Solis MdelC, Escobar C. Post-weaning protein malnutrition in the rat produces short and long term metabolic impairment, in contrast to earlier and later periods. Int J Biol Sci 2008;4:422-32.

81 Garofano A, Czernichow P, Bréant B. Beta-cell mass and proliferation following late fetal and early postnatal malnutrition in the rat. Diabetologia 1998;41:1114-20.

82 Cottrell EC, Seckl JR. Prenatal stress, glucocorticoids and the programming of adult disease. Front Behav Neurosci 2009;3:19.

83 Clark PM. Programming of the hypothalamo-pituitary-adrenal axis and the fetal origins of adult disease hypothesis. Eur $J$ Pediatr 1998:157:S7-10.

84 Sheppard A, Ngo S, Li X, et al. Molecular evidence for differential long-term outcomes of early life severe acute malnutrition. EBioMedicine 2017:18:274-80.

85 Dominguez-Salas P, Moore SE, Baker MS, et al. Maternal nutrition at conception modulates DNA methylation of human metastable epialleles. Nat Commun 2014;5:3746.

86 Hanley B, Dijane J, Fewtrell M, et al. Metabolic imprinting, programming and epigenetics - a review of present priorities and future opportunities. Br J Nutr 2010;104:S1-25.

87 Waterland RA, Garza C. Potential mechanisms of metabolic imprinting that lead to chronic disease. Am J Clin Nutr 1999;69:179-97.

88 Qin L-L, Luo B-A, Gao F, et al. Effect of exposure to famine during early life on risk of metabolic syndrome in adulthood: a metaanalysis. J Diabetes Res 2020;2020:3251275.

$89 \mathrm{Mu}$ R, Zhang X. Why does the great Chinese famine affect the male and female survivors differently? Mortality selection versus son preference. Econ Hum Biol 2011;9:92-105.

90 Thurstans S, Opondo C, Seal A, et al. Boys are more likely to be undernourished than girls: A systematic review and meta-analysis of sex differences in undernutrition [pre-review preprint]. medRxiv. 2020.

91 Li C, Lumey LH. Exposure to the Chinese famine of 1959-61 in early life and long-term health conditions: a systematic review and metaanalysis. Int J Epidemiol 2017;46:1157-70.

92 Niccoli T, Partridge L. Ageing as a risk factor for disease. Curr Biol 2012;22:R741-52

93 Kerac M, Bunn J, Chagaluka G, et al. Follow-up of postdischarge growth and mortality after treatment for severe acute malnutrition (FuSAM study): a prospective cohort study. PLoS One 2014:9:e96030.

94 Covid-19, food systems and nutrition: statement from our Co-Chairs - global panel. Available: https://www.glopan.org/covid-19-foodsystems-and-nutrition-statement-from-our-co-chairs/ [Accessed 15 May 2020]

95 World Food Programme. COVID-19 and the 5 major threats it poses to global food security. Medium, 2020. Available: https://insight. wfp.org/covid-19-and-the-5-major-threats-it-poses-to-globalfood-security-1c4da2ff6657 [Accessed 15 May 2020].

96 Roberton T, Carter ED, Chou VB, et al. Early estimates of the indirect effects of the COVID-19 pandemic on maternal and child mortality in low-income and middle-income countries: a modelling study. Lancet Glob Health 2020;8:e901-8.

97 Wang N, Chen Y, Ning Z, et al. Exposure to famine in early life and nonalcoholic fatty liver disease in adulthood. J Clin Endocrinol Metab 2016;101:2218-25.

98 Wang N, Ning Z, Xia F, et al. Exposure to famine in early life and chronic kidney diseases in adulthood. Nutr Diabetes 2018;8:1-7. 
99 Zheng X, Ren W, Gong L, et al. The great Chinese famine exposure in early life and the risk of nonalcoholic fatty liver disease in adult women. Ann Hepatol 2017;16:901-8. 